\section{$\underset{\substack{\text { hommes } \\ \text { \& migrations }}}{ }$}

\section{Hommes \& migrations}

Revue française de référence sur les dynamiques

migratoires

$1306 \mid 2014$

Ecriture et migration

\title{
Faïza Guène, Un homme, ça ne pleure pas
}

Paris, Fayard, 2014, 315 pages, 17,10€.

\section{Mustapha Harzoune}

\section{(2) OpenEdition}

1 Journals

\section{Édition électronique}

URL : http://journals.openedition.org/hommesmigrations/2826

DOI : 10.4000/hommesmigrations.2826

ISSN : 2262-3353

\section{Éditeur}

Musée national de l'histoire de l'immigration

\section{Édition imprimée}

Date de publication : 1 avril 2014

Pagination : 118-120

ISBN : 978-2-919040-27-8

ISSN : $1142-852 X$

\section{Référence électronique}

Mustapha Harzoune, "Faïza Guène, Un homme, ça ne pleure pas », Hommes \& migrations [En ligne], 1306 | 2014, mis en ligne le 06 août 2014, consulté le 22 septembre 2020. URL : http:// journals.openedition.org/hommesmigrations/2826 ; DOI : https://doi.org/10.4000/ hommesmigrations.2826

Ce document a été généré automatiquement le 22 septembre 2020.

Tous droits réservés 


\title{
Faïza Guène, Un homme, ça ne pleure
}

\section{pas}

Paris, Fayard, 2014, 315 pages, 17,10€.

\author{
Mustapha Harzoune
}

\section{RÉFÉRENCE}

Faïza Guène, Un homme, ça ne pleure pas,

Paris, Fayard, 2014, 315 pages, 17,10 €.

\section{NOTE DE L'ÉDITEUR}

Sélection 2014 de la 5édition du prix de la Porte Dorée.

1 Une ligne traverse la famille Chennoun: d'un côté, une certaine tradition, de l'autre, une forme de modernité. Le passage d'une position à l'autre se produit par le jeu du silence ou de la parole, le rejet ou l'attrait, le doute, des conflits intérieurs, des certitudes, des transformations et autant de tiraillements.

Dounia, l'aînée, est celle qui provoque la rupture. "Je crois que ma sœur a souvent eu envie de s'appeler Christine." En une formule, synthétique et drôle, le "processus de 'christinisation", Faïza Guène ramasse la marche émancipatrice de Dounia Tout est dit. Personne n'a trouvé "la bonne manière de l'aimer", comme il n'est pas sûr qu'elle ait su se faire aimer. Résultat, au moment où s'ouvre le récit, dix ans de séparation. Dounia incarne la figure de l'intégration labellisée, un parcours d'émancipation synonyme de reniement, de négation d'une partie de soi-même et des siens. Mais "à quoi bon?" demande le frère cadet, quand les bons élèves de la République sont victimes du " syndrome de Babar": "Babar aura beau marcher sur deux pattes, porter des costumes troispièces, un nœud papillon, et rouler dans une voiture décapotable, ce sera toujours un éléphant!" L'universalisme à la française serait-il du pipeau? 
3 Face à Dounia se dresse la figure de la mère gardienne du temple. Elle s'offusque, gronde, tempête, sanglote, se lamente et brandit l'arme de la "culpabilisation" pour faire rentrer dans le rang mari et progéniture.

4 Si cette arme n'est pas nécessaire à l'endroit de Mina, l'autre fille, soutien indéfectible et férocement hostile à Dounia, en revanche, à l'endroit de Mourad, elle s'est révélée efficace. Culpabilité et amour castrateur ont fait du fiston un puceau qui, à force de frustrations et d'angoisse, a développé une fâcheuse laxophobie. Solitaire par nécessité, Mourad s'est réfugié dans le savoir et dans les livres. C'est lui qui rapporte l'histoire familiale.

Professeur de français dans un collège de Montreuil, il partage "les mêmes cauchemars" que Dounia, certaines aspirations aussi, mais il préfère adopter une autre attitude.

Enfin, il y a ce père, celui qui ne pleure pas. Ou presque. L'homme est bon, attentif et aimant. Il jongle avec des valeurs emportées en héritage ou reçues en contrebande, avec des temps qui se chevauchent, des horizons incertains. Le silence est un refuge. Si son fils souffre de laxophobie, lui est frappé par une hémiplégie. Les corps parlent aussi chez Faïza Guène.

Que viennent faire ici les amours arc-boutées de Miloud, le cousin, et de Liliane, vieille bourgeoise du XVI ${ }^{e}$ parisien? Elle est riche, il est sans le sou. Elle est seule, délaissée par son fiston qui a réduit "l'amour maternel" à un tiroir-caisse, il est là, débordant d'énergie et réveillant en elle un cœur qu'elle croyait usé, un souffle trop tôt affaibli. Chacun trouve chez l'autre ce qui lui manque, ce qu'il faut pour alimenter une petite flamme d'amour, juste de quoi éclairer le chemin. "Y a pas d'embrouille, que de la débrouille, mon frère!"

8 Il faut se méfier de l'apparente facilité de ce texte aux dialogues nombreux et pertinents. Il y a fort à parier qu'au-delà du talent de l'auteure - qui évolue, se densifie, s'élargit -, de l'acuité du regard qu'elle pose sur le monde et ses contemporains, il y a beaucoup de travail et pas mal de suite dans les idées. Travail sur la langue d'abord: distance, dérision, humour, fausse légèreté. La langue, plus maîtrisée, soignée, conserve ce qu'il faut de «modernité » langagière : expressions arabes, verlan, mode scénario... Travail aussi sur la palette des personnages qui traduisent la volonté de ne pas enfermer le monde - la France métisse - dans un axiome unique et simplificateur. L'épaisseur des traits sert à souligner les ambivalences, les incertitudes, mouvements, dérives des uns et des autres.

9 Suite dans les idées aussi, avec ces thèmes de la liberté individuelle, du dialogue de la tradition et de la modernité, de la cohésion des familles confrontées à des injonctions normatives et contradictoires, du jeu des fidélités et des trahisons, de la question de ces identités qui, dans l'anonymat, combinent, "bricolent", concèdent, rejettent, inventent, réinventent... un rapport au monde et à soi.

10 Un homme, ça ne pleure pas? Pas sûr... tant que ce syndrome de Babar persistera. Comme il y a aussi de quoi pleurer aux douces promesses d'une réconciliation. Histoire de privilégier la débrouille sur les embrouilles! 